\title{
Atenção psicológica e umbanda: Experiência de cuidado e acolhimento em saúde mental
}

\section{Psychological attention and umbanda: Experience of care and mental health}

\section{Atención psicológica y umbanda: Experiencia del cuidado en la salud mental}

\author{
Fabio Scorsolini-Comin* \\ Universidade Federal do Triângulo Mineiro - UFTM, Uberaba, Minas Gerais, Brasil
}

\begin{abstract}
RESUMO
O objetivo deste estudo de caso é relatar a experiência do plantão psicológico desenvolvido em um terreiro de umbanda, com destaque para os processos de construção do cuidado e do acolhimento em saúde mental. O atendimento estruturou-se a partir da abordagem centrada na pessoa e de pressupostos do aconselhamento multicultural e da etnopsicologia. Cristal é uma jovem com um filho pequeno e reside com a mãe. No plantão, queixouse de intensa dor no peito e crises de pânico pelo medo de morrer em decorrência dessa condição, bem como dificuldades no relacionamento com a mãe. Os relatórios médicos não apontaram qualquer comprometimento cardíaco. No atendimento, foi discutida a questão da autonomia e o fato de que o ser humano possui algum poder sobre as determinações que o afetam, sendo este processo mais importante que o diagnóstico. A comunidade religiosa mostrou dificuldades de compreender suas queixas, mas abriu espaço para a escuta do seu problema. Conclui-se que o acolhimento oferecido pela comunidade e no espaço do plantão psicológico alinha-se ao movimento que apregoa a necessidade de diversificar os espaços de atenção psicossocial e de oferta de cuidados em saúde mental.
\end{abstract}

Palavras-chave: plantão psicológico, aconselhamento, saúde mental, umbanda.

\begin{abstract}
The objective of this case study is to report the experience of psychological emergency attendance developed in an Umbanda backyard, with emphasis on the construction processes of care and mental health care. The service was structured from the person-centered approach and assumptions of multicultural counseling and ethnopsychology. Cristal is a young girl with a young son and lives with her mother. On service complained of severe chest pain and panic attacks for fear of dying from this condition, as well as difficulties in the relationship with the mother. The medical reports did not show any cardiac involvement. The person-centered approach assumes the autonomy, including the human being has any power over the decisions that affect it, which is most important that the diagnosis process. The religious
\end{abstract}


community found it hard to understand their complaints, but made room for listening to their problem. We conclude that the reception given by the community and within the psychological emergency attendance aligns the movement that touts the need to diversify the spaces psychosocial care and the supply of mental health care.

Key-words: psychological emergency attendance, counseling psychology, mental health, umbanda.

\section{RESUMEN}

El objetivo de este estudio de caso es presentar la experiencia de la guardia psicológica desarrollada en el contexto de la Umbanda, con énfasis en los procesos de construcción de la atención y el cuidado de la salud mental. El servicio se estructuró desde el enfoque centrado en la persona y los supuestos de la orientación multicultural y etnopsicología. Cristal es una chica con un hijo pequeño y vive con su madre. Ella se queja de dolor aguda en el pecho y los ataques de pánico por miedo a morir a causa de esta enfermedad, así como las dificultades en la relación con la madre. Los informes médicos no mostraron afectación cardiaca. El enfoque centrado en la persona asume la autonomía, incluyendo el ser humano tiene ningún poder sobre las decisiones que la afectan, lo cual es más importante que el proceso de diagnóstico. La comunidad religiosa resultaba difícil de entender sus quejas, pero hizo espacio para escuchar su problema. Llegamos a la conclusión de que la recepción ofrecida por la comunidad y en la guardia psicológica se alinean el movimiento que proclama la necesidad de diversificar el espacio de atención psicosocial y la prestación de atención de salud mental.

Palabras-clave: guradia psicológica, aconsejar, salud mental, umbanda.

\section{Introdução}

O plantão psicológico é uma modalidade de atendimento profissional derivada do aconselhamento psicológico e desenvolvido no Brasil como possibilidade de escuta e acolhimento em situações de urgência, a partir da demanda da pessoa em sofrimento. O plantão estrutura-se na possibilidade de oferta de uma escuta qualificada, em tempo e espaço definidos em função da urgência do cliente. Tem como objetivo o acolhimento da queixa e a possibilidade de clarificação da mesma e de reflexões em torno das possibilidades de resolução do conflito ou de apoio emocional no momento em que o sofrimento se tornou insustentável. Há uma concordância que o atendimento em plantão pode ocorrer em um único encontro, não devendo o profissional ansiar ou esperar por um retorno, o que traz a necessidade de privilegiar aquele momento de interação como único na oferta de apoio psicológico (Bezerra, 2014; Gomes, 2008; Mahfoud, 2012; Perches \& Cury, 2013; Scorsolini-Comin \& Santos, 2013; Tassinari, Cordeiro, \& Durange, 2013).

O plantão psicológico é oferecido em diversas instituições, como escolas, distritos policiais e equipamentos ligados à promoção de saúde, sendo recente a sua descrição em comunidades religiosas 
como terreiros de umbanda. É por essa razão que tem recebido uma denominação específica para este contexto, a de plantão etnopsicológico (Scorsolini-Comin, no prelo). Mas a expressão plantão etnopsicológico não se refere apenas ao contexto institucional onde ocorrem os atendimentos psicológicos, mas fundamentalmente ao escopo desse serviço em uma dada comunidade, com suas características, crenças, padrões, costumes, formas de organização e socialização, elementos estes que devem ser pensados e incorporados na oferta de apoio psicológico.

No entanto, a aproximação desses espaços religiosos como campos de acolhimento emocional e de transmissão de práticas de cura e de saúde já vêm sendo apontados na literatura especializada, que destaca a umbanda como uma religião ligada ao assistencialismo e à solidariedade como uma de suas marcas constitutivas (Alves \& Seminotti, 2009). Embora haja um leque variado de expressão dessa religião em festas e demais rituais, um dos seus principais pilares é a caridade, representada pelos atendimentos espirituais ofertados aos consulentes por meio de médiuns que incorporam espíritos (como pretos-velhos, caboclos, baianos, exus e pombagiras) a partir do transe de possessão. Há que se referir que a umbanda é considerada uma religião genuinamente brasileira (Concone, 1987), surgida no Rio de Janeiro por volta dos anos de 1920 e 1930, ao mesclar elementos da cultura branca (português colonizador), negra (escravos) e indígena, além de aspectos do catolicismo (culto aos santos), dos cultos africanos (crença nos orixás, rituais) e do espiritismo kardecista (transe de possessão, caridade) (Leal-deBarros, 2013; Macedo, 2014; Macedo \& Bairrão, 2011).

O plantão psicológico desenvolvido na comunidade de terreiro em apreço ocorre a partir da inter-relação entre elementos do aconselhamento multicultural, da abordagem centrada na pessoa e da etnopsicologia. Embora tais pressupostos teóricos possam parecer, em um primeiro momento, distantes, têm se mostrado relevantes na estruturação da oferta de apoio psicológico às pessoas que participam da comunidade religiosa retratada neste estudo de caso. O aconselhamento multicultural (Lee, Rosen, \& Burns, 2013; Sehgal, Saules, Young, Grey, Gillem, \& Nabors, 2011), fortemente desenvolvido nos Estados Unidos para o atendimento de diferentes etnias, culturas e imigrantes, por exemplo, destaca a necessidade de o conselheiro (ou terapeuta) incorporar elementos da cultura de referência do cliente para poder ouvi-lo com mais propriedade, trazendo à baila os elementos culturais que constituem o cliente e sua comunidade. Assim, toda orientação deve partir desse universo de crenças, saberes e práticas no qual o cliente está imerso, não podendo 0 aconselhamento partir de elementos externos a essa comunidade cultural, evitando o olhar etnocêntrico por vezes atribuído a quem se coloca "de fora" da comunidade de referência. 
Em uma consideração próxima, a etnopsicologia destaca a necessidade de se compreender como determinadas práticas culturais são construídas, transmitidas e perpetuadas no psiquismo de seus membros, sendo que a ciência psicológica deve sempre conhecer a fundo as regularidades sociais, as formas de socialização, cuidado e transmissão de saberes em cada comunidade para que possa tecer conclusões que justamente incorporem esses elementos na compreensão de uma dada comunidade ou de um grupo de pessoas (Leal-de-Barros \& Bairrão, 2010; Pagliuso \& Bairrão, 2011). As crenças, os costumes, as divindades e o modo de ser dessa comunidade são representados nos gestos e nas palavras dos participantes, sendo tarefa do etnopsicólogo conhecê-los para poder intervir tendo esse modelo como referência (Macedo, Bairrão, Mestriner, \& Mestriner Junior, 2011). O trabalho do etnopsicólogo assemelha-se ao do antropólogo justamente pela necessidade de "estar dentro" da comunidade para poder vivenciá-la, compreendê-la e, posteriormente, analisá-la.

$\mathrm{Na}$ abordagem centrada na pessoa, Rogers (1977) sustenta que a promoção do crescimento pessoal ocorre na relação terapêutica se existirem determinadas atitudes consideradas necessárias e suficientes, haja vista que a pessoa possui dentro si diversos recursos para buscar a sua autoafirmação e a sua autorrealização. Assim, cabe ao profissional proporcionar um clima de atitudes psicológicas facilitadoras responsáveis por promover certas modificações de personalidade e do comportamento, como ter um sentimento de consideração positiva incondicional pelo cliente e experimentar uma sensação de compreensão empática acerca do relato. A essas condições, acrescenta-se a atitude de congruência ou autenticidade, que se refere ao fato de o terapeuta ser ele mesmo, estar em contato com suas percepções e sentimentos, podendo demonstrá-los e utilizá-los no contato com o cliente (Rogers, 2001).

Assim, o apoio psicológico oferecido em terreiro de umbanda parte da confluência desses três aportes teóricos. A etnopsicologia oferece subsídios para refletirmos sobre o contexto de investigação, delineando os principais aspectos que compõem essa comunidade, suas crenças, costumes, o modo como a umbanda contribui para caracterizar esse espaço social. Os elementos etnopsicológicos definidos na comunidade são evocados nas intervenções realizadas por meio de menções, expressões e formas de ser, o que deve ser considerado em uma escuta psicológica atenta a esses aspectos (Macedo et al., 2011). O aconselhamento multicultural, por sua vez, destaca a necessidade de considerar essas características dentro do processo de ajuda, ou seja, deve-se remeter sempre à qual comunidade estamos nos referindo, quais suas principais demandas, fontes de ajuda existentes e marcadores culturais que definam esses participantes e os legitimem (Sehgal et al., 2011). 
A abordagem centrada na pessoa oferece um suporte para as intervenções, em um modelo que considera a relação entre cliente e profissional como fundante, sendo as atitudes do terapeuta muito importantes na condução do processo (Amatuzzi, 2008; Justo, 2002; Rogers, 2001; Rosenberg, 1977a). A premissa é a de que qualquer pessoa possui uma tendência inata ao crescimento, ao amadurecimento, a um maior conhecimento de si. As intervenções centradas na pessoa, dessa forma, priorizam tais atitudes como condições para a promoção do bem-estar e para a experiência do crescimento pessoal e da autorrealização (Scorsolini-Comin, 2014). Por recobrir técnicas não diretivas e explorar o modo como os significados são vivenciados pelo cliente, em uma suspensão tanto dos juízos de valor, quanto de realidade; trata-se de uma abordagem adequada ao contexto no qual ocorre a oferta do plantão psicológico. O plantão psicológico também tem sido pensado como uma modalidade de atenção no contexto da saúde mental (Gomes, 2008) e da promoção de saúde. A Reforma Psiquiátrica, reconhecida no Brasil a partir da Lei 10.216, de 6 de abril de 2001, foi um marco no sentido de promover 0 atendimento comunitário a pacientes psiquiátricos ou em sofrimento mental, anteriormente cronificados em asilos e hospitais psiquiátricos. Com a criação dessa lei, houve gradativamente a diminuição dos leitos psiquiátricos e das internações, priorizando um modelo de atendimento no qual o paciente deve ser integrado à sociedade e à comunidade em que vive, com direito à convivência familiar. Desse modo, a reforma destaca a necessidade de desinstitucionalização em favor de um atendimento comunitário que pode ocorrer em equipamentos alternativos como hospitais-dia, hospitais-noite, centros de convivência, centros de atenção psicossocial, ambulatórios de emergências psiquiátricas, residências terapêuticas e outras possibilidades de cuidado (Barroso \& Silva, 2011; Nascimento, Scorsolini-Comin, \& Peres, 2013; Vidal, Bandeira, \& Gontijo, 2008), como destacamos neste estudo. Essa assistência deve ser orientada pelos princípios norteadores do Sistema Único de Saúde, ou seja, universalidade, equidade e integralidade (Cardoso, 2014).

A partir dessas considerações, o objetivo deste estudo de caso é relatar a experiência do plantão psicológico desenvolvido em um terreiro de umbanda, com destaque para os processos de construção do cuidado e do acolhimento em saúde mental.

\section{Método}

Trata-se de um estudo de caso (Stake, 2000) amparado na abordagem qualitativa de pesquisa. Entre os pressupostos do estudo de caso está a necessidade de que a experiência particular destacada 
conserve uma relevância em termos de sua aplicação ou ressonância para outros estudos e práticas. Podem ser priorizados elementos específicos do caso que apontem para novos conteúdos ou mesmo para um maior arcabouço teórico dentro de um modelo de referência. O emprego do estudo de caso neste relato de experiência se justifica pelos poucos e esparsos estudos sobre as comunidades religiosas de terreiro sob a égide do apoio psicológico ofertado às pessoas da comunidade (Alves \& Seminotti, 2009). Dentro dessas nuanças, o estudo em retrato revela não apenas o modo como o plantão psicológico é desenvolvido nesta comunidade, mas, também, quais as possibilidades de reflexão que esse caso específico desperta para os estudiosos da umbanda e principalmente, para os pesquisadores no campo do plantão psicológico centrado na pessoa e na área de saúde mental. Este estudo está amparado nas disposições éticas para pesquisas envolvendo seres humanos e sua realização foi aprovada pelo Comitê de Ética em Pesquisa da instituição de origem do autor.

A experiência retratada refere-se a um atendimento em plantão psicológico ocorrido em uma comunidade de terreiro de umbanda localizada na região periférica de uma cidade de médio porte do interior do Estado de São Paulo. Este terreiro existe há mais de dez anos e congrega consulentes vindos de diferentes regiões da cidade, com predomínio de pessoas da própria comunidade. O terreiro localiza-se na casa do "pai de santo", em dois grandes cômodos: a garagem acolhe os consulentes (chamados de assistência) e em outra sala, ao lado da garagem, ocorrem os rituais de transe de possessão, festas, "giras" de desenvolvimento mediúnico para médiuns iniciantes e os atendimentos espirituais (consultas abertas ao público).

Os atendimentos psicológicos foram iniciados a partir de uma demanda existente na comunidade por acompanhamento de alguns casos por profissionais de Psicologia (Scorsolini-Comin, no prelo). Os profissionais da Psicologia responsáveis por esses atendimentos foram inseridos na comunidade a partir de pesquisas sobre 0 universo umbandista realizadas no terreiro em apreço. Desse modo, a comunidade já conhecia o trabalho de alguns psicólogos que haviam realizado suas pesquisas de Iniciação Científica, Mestrado e Doutorado naquele espaço, pois se tratava de um terreiro que abria suas portas para a realização dessas investigações, sendo toda a comunidade muito solícita e acostumada com a presença dos pesquisadores nas giras, consultas e também na casa do "pai de santo". Muitas pessoas da comunidade já haviam conversado com esses profissionais, cedido entrevistas e participado, de algum modo, das pesquisas ali desenvolvidas. $\mathrm{Na}$ ocasião do início dos atendimentos psicológicos, os profissionais estavam desenvolvendo pesquisas sobre as consultas mediúnicas, as práticas de saúde veiculadas nesses atendimentos e sobre os processos desenvolvimentais dos médiuns da casa, o que fazia com que esses 
pesquisadores frequentassem 0 terreiro semanalmente, com realização de observações, entrevistas, registros em diário de campo, vídeos e fotografias naquele contexto. Com o tempo e o prosseguimento da coleta de dados na instituição, esses psicólogos passaram a ser questionados, em diferentes momentos e por diferentes frequentadores, se poderiam atender algumas pessoas da comunidade na modalidade de psicoterapia. O pedido dessas pessoas era por atendimento psicológico, uma vez que sabiam que aqueles pesquisadores eram profissionais de Psicologia. Com o aceite da proposta por parte dos pesquisadores e também como forma de prestar um serviço a uma comunidade que sempre colaborava com as pesquisas de diversas pessoas, passaram a ser desenvolvidos atendimentos psicológicos individuais a cargo desses profissionais, com a criação de um plantão psicológico com o objetivo de atender à demanda espontânea nos mesmos dias e horários em que o terreiro ficava aberto ao público. Nesse plantão, realizado uma vez por semana, são atendidas pessoas em sofrimento e que necessitam de apoio urgente, não havendo necessidade de agendamento. As pessoas atendidas podem ser ou não as mesmas que estão se consultando com os médiuns incorporados, haja vista que o plantão está aberto a pessoas da comunidade, ou seja, aquelas que frequentam o terreiro em quaisquer dias e horários. Como destacado anteriormente, este plantão organiza-se a partir da abordagem centrada na pessoa, reunindo pressupostos do aconselhamento psicológico multicultural e da etnopsicologia que também serão evocados como referenciais teóricos para a discussão do estudo de caso. O plantão foi divulgado na comunidade pelos próprios profissionais e também pelo pai-de-santo. Quando alguém pedia apoio psicológico, indicava-se o espaço do plantão para que uma primeira conversa fosse realizada. Algumas pessoas eram convidadas diretamente pelo pai-de-santo para serem atendidas, outras buscavam o serviço por conhecerem os psicólogos envolvidos e por apresentarem alguma demanda psicológica.

\section{0 caso de Cristal}

A fim de preservar o registro do atendimento, o relato do caso atendido pelo autor será em primeira pessoa. Cristal (nome fictício) tem cerca de 20 anos de idade, atua como auxiliar de cozinha e possui um filho de dois anos de idade. Reside com a mãe e o filho em uma região de periferia, próxima ao terreiro onde ocorrem os plantões. Nosso primeiro contato foi quando uma médium incorporada, durante a consulta espiritual de Cristal, pediu que eu conversasse com a moça, pois ela estava "perturbada". Fui chamado pela entidade incorporada (em transe de possessão) e 
esta me solicitou que atendesse Cristal, pois eu era "capa branca" (profissional de saúde, psicólogo). A partir da demanda por atendimento, disse à moça que poderia atendê-la durante o plantão psicológico que ocorre às sextas-feiras no próprio terreiro, sem necessidade de fazer agendamento. Também informei que se tratava de um atendimento gratuito, dentro de um projeto de extensão universitária que desenvolvo naquela comunidade.

Nesse primeiro dia, algumas pessoas da comunidade vieram me contar sobre o que sabiam da moça, afirmando que ela era "louca" e "perturbada". Uma das pessoas me disse que se tratava de um "caso de $P Q U$ ", em referência à necessidade de atendimento em Psiquiatria pela suspeita de adoecimento mental. Era a primeira vez que eu a via no terreiro, mas a comunidade já a conhecia há pelo menos um mês, devido aos atendimentos espirituais pelos quais vinha passando. Nesse mesmo dia, de modo informal, conversei um pouco com Cristal, já que o horário do plantão já havia encerrado (por volta das 22h30). Esta me pareceu uma jovem em conflito e bastante ansiosa, já que conversava efusivamente com todas as pessoas que circulavam na comunidade. A cada pessoa que se aproximava, ela fazia alguma pergunta, "puxava" assunto, tentava se aproximar. Perguntava se poderia adicionar as pessoas em sua conta em uma rede social e fazia comentários por vezes "desconcertantes", fazendo com que todos notassem a sua presença. Demonstrava necessidade de contato físico com as pessoas que trabalhavam no terreiro (médiuns e auxiliares). Senti receio de atendê-la, nesse primeiro momento, pela quantidade de perguntas que me fazia (de cunho pessoal) e por certa aproximação que eu considerava excessiva para alguém que eu acabava de conhecer. Respondi a algumas perguntas, mantendo minha postura de interesse e consideração pelo seu relato. Eu a revi uma semana depois, no período da manhã. $O$ atendimento em plantão seria à noite, haja vista que pela manhã atendo outros clientes em acompanhamento psicoterápico na mesma comunidade. Ao me avistar na comunidade, Cristal começou a me questionar se o atendimento seria naquele momento: "Nossa, você chegou cedo!". Disse que tinha marcado atendimento com outras pessoas da comunidade naquela manhã, mas que à noite poderíamos conversar, conforme combinado. Mesmo assim foi me contando alguns acontecimentos de sua vida. Mostrou-me seu filho, que estava brincando perto dela. Disse que estava com dores no peito e que achava que ia morrer. Os médicos haviam dito para ela que não tinha qualquer problema de ordem cardiológica, mas sim de ordem emocional, que se tratava de um problema "psicológico". No entanto, não haviam feito qualquer encaminhamento ou recomendação para que ela procurasse ajuda psicológica. Contou-me que havia apanhado da mãe na noite anterior e que havia chamado a polícia para prendêla por violência doméstica. O motivo do desentendimento foi que 
ela estava sentindo dores no peito e que a mãe não quis levá-la ao serviço de pronto-atendimento. Mesmo com a queixa, a mãe não acreditou na filha e passou a agredi-la, a fim de que dissuadisse da ideia de procurar um médico aquela hora da noite. Cristal dizia insistentemente que tinha muita dor no peito, ao que o pai-de-santo, que observava a conversa, afirmava que isso era uma coisa "da sua cabeça", que não era real. Nessa conversa observei um pouco da interação de Cristal com o seu filho. Ela parecia "esquecer-se" dele, deixando-o brincar e explorar o ambiente livremente, sem supervisão ou qualquer preocupação. Em certo momento, eu a adverti que o filho pudesse correr para a rua e ela não demonstrou preocupação, apesar de seguir o filho em direção ao portão de saída do terreiro. Assim que meu primeiro cliente chegou, despedi-me dela e disse que conversaríamos à noite.

Cristal chegou no início do plantão, parecia bem disposta e foi a primeira a ser atendida. Comecei perguntando-lhe se ela já havia sido atendida por algum psicólogo antes ou se ela sabia o que fazia um psicólogo. Mostrou certa confusão entre Psicologia e Psiquiatria, afirmando que ambos "cuidavam da cabeça" e receitavam remédios. A sua queixa principal se relacionava a uma intensa dor no peito e um medo recorrente de morrer em função desse mal-estar. Disse ter se consultado com 15 médicos ao longo de dois meses (quando a queixa surgiu) e que todos foram categóricos em afirmar que ela não possuía qualquer comprometimento cardíaco. Exames foram realizados e nada detectado. Alguns chegaram a dizer que ela possuía "gases" e lhe receitaram um remédio que alivia os sintomas da dor. Essa dor passa quando toma o remédio, mas volta, segundo seu relato. Quando sente essa intensa dor no peito, entra em pânico com a possibilidade de morrer. Em sua fala, destaca que possui síndrome do pânico. Eu questiono sobre o que ela pensa ser essa síndrome, ao que ela me responde ser um estado de ansiedade em função do medo que sente de morrer. A dor no peito lhe causa medo de morrer e este sentimento desperta o seu pânico. O seu medo é deixar seu filho pequeno e não poder acompanhar o seu crescimento. Afirma que conhece uma pessoa que teve pânico (uma pessoa da própria comunidade) e que se curou após ficar muito tempo internado. Perguntou-me várias vezes se tinha mesmo o transtorno de pânico, ao que respondia que tínhamos que conversar mais um pouco, mas que compreendia que ela se sentia muito ansiosa quando começava a sua dor no peito.

Em seu histórico, comenta que seu pai morreu em decorrência de um infarto. Apresenta o caso de uma conhecida sua que também sofreu um infarto fulminante. Segundo seu relato, os médicos nunca advertiram essa conhecida sobre qualquer problema cardíaco. Quando the perguntei sobre quais passos gostaria de tomar a partir daquele encontro, disse-me que queria se consultar com um 
cardiologista (pois os demais médicos com que se consultou eram plantonistas, e não especialistas) e depois se internar (não sabe delimitar muito bem como seria essa internação), possivelmente em uma clínica psiquiátrica. Essa internação, segundo ela, seria para que as pessoas pudessem ajudá-la a tirar as ideias fixas da sua mente, o seu medo de morrer. Fala com bastante tranquilidade sobre a necessidade de se internar para poder se tratar.

Comento que esse seu medo de morrer a tem levado a adotar uma série de comportamentos que fazem com que a sua vida esteja marcada pelas restrições e preocupações excessivas. Ao procurar vários médicos e não acreditar na ausência de um comprometimento cardíaco, busca intensamente um profissional que possa descobrir uma possível doença. Ao mesmo tempo, não quer estar doente e teme morrer. Questiono se viver com tanto medo de morrer não seria semelhante a morrer, de fato. Ela concorda e diz que não havia pensado dessa forma ainda.

Durante este atendimento, uma pessoa bateu na porta da sala e disse que a mãe de Cristal havia ligado no terreiro e reclamado que a moça havia deixado o filho sozinho na rua para ir ao terreiro. A mãe solicitava que a filha voltasse imediatamente para sua casa para cuidar do filho. Eu disse a ela que poderia sair, resolver a situação e depois retornar, que eu estaria ali à sua espera. Destaquei que ela poderia vir em outro dia também. No entanto, a sua opção foi por permanecer no atendimento, destacando que a mãe estava mentindo, que seu filho não estaria em perigo. Em suas palavras, a mãe cuidava melhor do filho do que ela e essa ligação telefônica era apenas porque ela não aceitava que Cristal frequentasse o terreiro. Destaquei novamente a possibilidade dela se ausentar e depois retornar, ao que ela não aceitou. Senti-me angustiado pela possibilidade de o filho estar em risco, mas pensei que a avó deveria estar com o neto naquele momento, já que havia ligado. Ao final do atendimento, Cristal permaneceu no terreiro e foi se consultar com um médium. Depois ficou no espaço dedicado aos atendimentos espirituais, andando e conversando com algumas pessoas. Ao final dos atendimentos e quando os médiuns já desincorporados se preparavam para fazer o encerramento da gira (sessão de umbanda), a mãe de Cristal apareceu para dar uma notícia para a filha. Esta senhora, Maria (nome fictício), com pouco mais de 50 anos e com aparência suja e maltratada, descalça e visivelmente descontrolada, entrou gritando pela filha e afirmando que o neto havia sido levado embora pelo pai da criança. Cristal começou a chorar e então as convidei para conversar em outro espaço do terreiro, a fim de que elas não ficassem expostas diante da comunidade formada pelos médiuns. Nessa conversa, Maria disse que Cristal era irresponsável, que sua queixa de saúde não tinha fundamento e que ela tinha total condição de trabalhar e se 
responsabilizar pelos cuidados com a criança. Cristal chorava muito e dizia que sentia sim as dores no peito e que não conseguia trabalhar, mas não enfrentava a mãe. Maria, por sua vez, destacava que iria bater em Maria quando esta voltasse para casa e que já havia desistido da filha. Eu destaquei para Maria que bater na filha não resolveria o problema e que ela deveria apoiar a filha, pois esta estava buscando auxílio. Eu disse que havia conversado com ela naquele dia e que poderia atendê-la outras vezes, mas que seu apoio era fundamental para que ela pudesse melhorar. Destaquei que Maria poderia também ser atendida no plantão na semana seguinte, que eu estaria lá para conversar com ela, caso desejasse.

A mãe estava muito abalada e me contou algumas passagens de sua vida, destacando que o seu esposo havia falecido, que outros parentes próximos também haviam falecido e que ela teve que cuidar dos filhos mesmo com tanta tristeza e sem apoio familiar. A queixa da filha era destacada por ela como uma "frescura" e, caso fosse uma doença, que deveria interná-la, a fim de que tivesse paz. Contou que o filho de dois anos chamava a mãe de louca e que chamava a avó de mãe, reconhecendo a sua genitora como se fosse uma irmã. A mãe falava da filha como se ela não estivesse ali. Reclamava que Cristal deveria ser mais responsável, que era uma jovem bonita e sadia, que teria que fazer a sua própria vida. Maria me parecia muito angustiada, mas ouvia as minhas intervenções. Despedimonos quando notei que a mãe estava um pouco mais tranquila. Disse para Cristal que ela deveria ir para casa com sua mãe e que, no dia seguinte, quando estivessem mais calmas, deveriam conversar sobre o que ocorreu e sobre o filho, que estava sob os cuidados do pai.

\section{Discussão}

A primeira angústia em relação ao caso que pode ser despertada no interlocutor é o enquadramento do mesmo como sendo da ordem da "saúde mental", da "Psiquiatria", do atendimento medicamentoso específico, da contenção do sofrimento e do encaminhamento a algum equipamento de saúde mental específico, como um CAPS (Centro de Atenção Psicossocial), com uma criteriosa avaliação diagnóstica para definir a melhor intervenção, em um pressuposto biomédico e oposto àquele centrado na autonomia (Amatuzzi, 2008). Estaria Cristal perdendo seu contato com a realidade? Tratava-se de um caso de adoecimento mental? O que seriam essas crises de dor no peito e de pânico relatadas por Cristal? Poderiam ser essas queixas acolhidas no plantão? Quais os encaminhamentos desse caso? Qual o diagnóstico desse caso? - perguntariam muitos dos profissionais de saúde. 
No entanto, na abordagem centrada na pessoa, há uma severa crítica a essa "aparente necessidade" diagnóstica, tal qual um descritor identitário anexado ao caso. Rogers (2001) é contundente em afirmar que o diagnóstico em nada ajuda no tratamento se as condições necessárias e suficientes para uma pessoa buscar seu crescimento pessoal não estiverem presentes e facilitadas pelo terapeuta. A abordagem centrada na pessoa parte do pressuposto da autonomia, que compreende que o ser humano possui algum poder sobre as determinações que o afetam, sendo este poder mais importante que as determinações ou diagnósticos (Amatuzzi, 2008). Para este autor, enquanto no pressuposto determinista a identificação de um diagnóstico conduz a uma estratégia para uma intervenção que promova a mudança esperada, o pressuposto da autonomia considera que na tendência ao crescimento pessoal deve-se dar atenção aos significados presentes em uma relação compreensiva, valorizadora e honesta que promova a autonomia crescente. "Pois, se o cliente é realmente uma pessoa que luta para ser ela mesma e se permitir sêlo - e não apenas o portador de uma neurose (...) -, isto não deverá ser igualmente verdadeiro para nós mesmos?" (Rogers, 1977, p. 16). Para Rogers (1977), o processo psicoterapêutico consiste na tomada de consciência dos modos inadequados de percepção, na aprendizagem de percepções corretas e satisfatórias e na apreensão de relações entre essas percepções. A partir dessa definição, a terapia seria um diagnóstico contínuo ao longo do processo terapêutico e não algo anterior a esse processo, ocorrendo na vivência experienciada do cliente (Bommert, 1987), ou seja, terapia e diagnóstico seriam processos simultâneos. O diagnóstico, dentro dessa abordagem, poderia exercer uma influência negativa sobre 0 sentido da responsabilidade pessoal do cliente (Justo, 2002). Assim, a descrição de Cristal como em adoecimento mental pouco nos esclareceria sobre seu tratamento. Tratava-se, sim, de um caso de saúde mental, mas de busca de saúde mental. Cristal encontra-se aflita, angustiada, aceita ser ajudada, comparece ao atendimento, quer permanecer no atendimento mesmo com a insistência da mãe para que volte para casa, consulta-se posteriormente com um médium incorporado, encontra no espaço do terreiro um acolhimento importante. Cristal permite-se criar vínculos - com as pessoas da comunidade, com o pai-de-santo, com o terapeuta que a atende no plantão. Mostra-se o tempo todo afetiva e com desejo de ser cuidada, bem-quista, valorizada. No início de seu relato, demonstra que a dificuldade de relacionamento com a mãe remonta à sua infância, quando se sentia preterida em relação aos irmãos. Assim, a dificuldade de se aproximar da mãe não se refere aos episódios recentes de sua queixa, mas a uma vincularidade que atravessa 0 seu desenvolvimento. No entanto, a comunidade a compreendia e interpretava como alguém que precisava "firmar a cabeça", não 
chegando a constituir um "diagnóstico", mas um disparador do que poderia ser feito por ela no terreiro e do cuidado prestado dentro da comunidade. Em um atendimento etnopsicológico, era preciso ouvir esse "diagnóstico" que circulava nas consultas com as entidades e nos relatos das pessoas que conheciam o seu caso, o que abria a possibilidade de compreender Cristal como alguém que teria um espaço no terreiro, pois seu problema era de ordem espiritual e poderia ser "tratado" nas giras de atendimento mediúnico. Ela estava no terreiro para "firmar a sua cabeça" para que pudesse, futuramente, receber os guias a partir do transe de possessão.

No entanto, o seu encaminhamento para o plantão mostrava que as suas queixas poderiam ser, também, acolhidas e cuidadas no breve espaço do atendimento psicológico. O terapeuta não julgou nem criticou as demandas de Cristal, mas convidou-a a refletir sobre a repercussão desses eventos em sua vida e no relacionamento com a mãe e com o seu filho. A consideração positiva incondicional, responsável por compreender Cristal como uma pessoa em busca de sua autorrealização e do seu bem-estar, foi importante para que o terapeuta não levantasse questionamentos acerca da veracidade ou não do seu relato. Seria verdadeira essa dor no peito, existente a despeito das comprovações médicas? Desse modo, não interessa ao atendimento psicológico se Cristal possui ou não um problema cardíaco, mas como essa queixa pode ser acolhida por um profissional sem que o mesmo questione a sua veracidade (Justo, 2002), como fazem as demais pessoas, como a mãe e os médicos que a atenderam. Ao dizerem "isso não é nada, é da sua cabeça", não promovem uma escuta genuína de Cristal, mas sim desconstroem o seu relato a partir de um exame "diagnóstico" que atesta que não existe problema que justifique a dor. Para o que não se pode justificar, o rótulo "psicológico" parece sustentar uma gama de possibilidades que encontraram no plantão um espaço de expressão e de acolhimento. Cristal estava sendo ouvida e essa escuta a fazia permanecer no atendimento mesmo com a ligação da mãe - não necessariamente porque fosse negligente com o filho, mas porque era necessário falar, era necessário ser ouvida por alguém que se interessasse pelo seu relato, pela sua dor. A presença genuína do terapeuta pode ter ajudado Cristal a entrar em contato com a sua queixa, que estava para além da dor no peito, mas recobria a sua história familiar, a ausência da mãe e a preocupação em se vincular com o filho. Também o terreiro, como espaço de cuidado, oferecia apoio para que ela pudesse se expressar, buscar ajuda e se organizar. Em uma leitura etnopsicológica, tratava-se de buscar auxílio em um local que já era considerado culturalmente como destinado a oferecer apoio e orientação nas mais diversas situações de sofrimento. A atenção psicológica, nesse sentido, beneficiava-se dessa associação, facilitando com que as pessoas 
pudessem ser atendidas naquele contexto específico.

$\mathrm{O}$ aparente enquadramento de Cristal em uma categoria diagnóstica a priori foi desfeito pela ancoragem na abordagem centrada na pessoa. O embate travado entre Rogers e a Psiquiatria por muitos anos conferiu à Psicologia a possibilidade de escuta em saúde mental para além dos diagnósticos (Rogers, 1977). E conferiu ao psicólogo a possibilidade de compor as equipes de serviços de saúde mental, por vezes coordenando esses equipamentos e não se submetendo ao domínio da Psiquiatria. Não se trata, pois, de recriminar o movimento diagnóstico ou de não legitimá-lo, mas de não priorizálo no atendimento psicológico tal como desenhado neste caso, notadamente no espaço do plantão, que pode se constituir em um único encontro, na maioria das vezes. Como destacado por Abelha et al. (2014) ao tratar do tratamento de esquizofrênicos, "o diagnóstico psiquiátrico, embora importante, não pode ser considerado suficiente para prever os resultados da recuperação dos pacientes" (p. 144). Ao ouvir Cristal como possuindo pânico, opera-se uma redescrição da cliente - a Cristal com pânico, e não mais a Cristal que estava em sofrimento e que buscou o plantão para diminuir a sua ansiedade diante das dores que sentia. O diagnóstico, na abordagem centrada na pessoa, pode distanciar o terapeuta do cliente, dificultando a consideração positiva incondicional e mesmo a assunção da empatia. A necessidade de Cristal "firmar a sua cabeça", em contrapartida, era compreendida como algo "comum" no terreiro, de modo que a sua "perturbação" ocupava um lugar na comunidade e que tinha um cuidado especial a ser devotado por quem assume a posição de cuidador. Os médiuns incorporados a ajudariam e a comunidade a aceitaria como uma participante que precisava de ajuda, assim como os diversos frequentadores das giras.

Um ponto importante deste caso foi a mobilização que Cristal criou em toda a comunidade centralizada no terreiro. Seu caso era conhecido de muitas pessoas, tanto consulentes como médiuns. No dia do atendimento em plantão, muitas pessoas conversavam e diziam que nada podiam fazer para ajudá-la, pois a mãe dela não queria que ela frequentasse o terreiro. Diziam: "se a mãe não quer que ela frequente, ela não pode vir. E isso não é problema do terreiro". Um dos médiuns afirmou: "ela não pode se desenvolver mediunicamente se a mãe não quiser ou for contra". Mas nunca houve relato de uma pessoa que começou a desenvolver a sua mediunidade (ou seja, participar ativamente das giras) com a "autorização" de mãe, pai ou responsável. No entanto, Cristal é maior de idade e não precisaria da tutela da mãe, a não ser em relação aos cuidados com o filho, pois Maria é quem provavelmente ficaria com o menino enquanto ela estivesse no terreiro. Alguns comentavam que Cristal não deveria "girar", ou seja, desenvolver a sua mediunidade no terreiro, pois estava muito perturbada e deveria se cuidar antes 
desse processo. Há que se destacar que Cristal estava frequentando o terreiro para desenvolver a sua mediunidade, segundo fora sugerido em um dos atendimentos espirituais pelos quais passou. Outros, ainda, destacavam que nada poderiam fazer por ela, que era um caso para um psiquiatra. O que se pode observar é que o seu "problema de cabeça" fez com que os médicos e os médiuns a indicassem para o atendimento psicológico, mas também fez com que ela pudesse buscar o terreiro por interpretar essa demanda como sendo da ordem espiritual ou que pudesse ser curada pelos médiuns incorporados. Todas as formas de cuidado e de explicação do seu caso concentramse nessa "cabeça", o que nos permite apreender o corpo em seu significado cultural.

Para Csordas (2008), o corpo é a base da cultura e do sujeito, de modo que a corporeidade é fundamental para se compreender a experiência humana na cultura. Desse modo, essa cultura poderia ser compreendida e interpretada a partir da corporeidade, de modo que a "cabeça" ocuparia um papel de destaque nesse contexto religioso, algo presente em diversos rituais como o "amaci" de cabeça (banhos ou lavagens para fortalecer a cabeça, realizados geralmente quando se começa o desenvolvimento mediúnico), a "raspagem" da cabeça (sobretudo no candomblé), conhecer o "santo de cabeça" (orixá protetor), além de diversas menções nos rituais, como "firmar a cabeça" (concentrar-se) e "bater a cabeça" (reverenciar as entidades). Cristal não teria a cabeça "firme", pois estava dispersa, confusa, sem paz de espírito, não sendo considerada por algumas pessoas como alguém que poderia se desenvolver como médium. Em contrapartida, como afirmado pelas entidades nas consultas observadas nessa comunidade, muitas vezes o desenvolvimento mediúnico é "indicado" como forma de fortalecer a cabeça da pessoa e fazê-la retornar ao seu equilíbrio. Uma das leituras é a de que a cabeça da pessoa poderia estar "afetada" pelo fato de que os espíritos queriam "trabalhar" (atender, ajudar pessoas) e estavam fazendo com que a pessoa cuidasse da sua mediunidade para, então, recebê-los (pelo transe de possessão) e atender aos consulentes no terreiro.

A experiência de Cristal não apenas passa pelo corpo (dor no peito, cabeça desorganizada), mas essa corporeidade aparece prenhe de sentimentos, afetos, crenças, percepções, desconfianças (quanto ao diagnóstico) e constituem a dimensão da pessoa. Cristal passa a ser vista como a moça que não possui a "cabeça firme" e que apresenta dores injustificáveis (do ponto de vista fisiológico) no peito. Quando os frequentadores dizem que ela precisa "firmar a cabeça" referemse a organizar-se como pessoa, ou seja, falam de uma experiência corporificada que tem como ponto de referência a cultura umbandista, tal como tratada por Csordas (2008). O corpo na umbanda traz à tona as noções de saúde e doença, sendo um veículo 
para a manifestação do transcendente (Jorge, 2013). Desse modo, a comunidade compreende a sua "cabeça" como necessitando ser cuidada, orientada, a fim de que possa fazer parte da equipe de médiuns e sanar as suas dores no peito. O corpo emerge como espaço de cura, sendo a cabeça a depositária desse processo. "Cuidar da cabeça" aliviaria a dor no peito e também a ajudaria em seu processo de desenvolvimento espiritual. É nesse sentido que o corpo sustenta-se como ponto de partida metodológico para a compreensão da psicopatologia cultural (Telles \& Moreira, 2014), devendo ser narrado em termos de suas repercussões e leituras possíveis na umbanda e no contexto comunitário em apreço. Esse cuidado, que se refere ao acolhimento e à cura que ocorrem no espaço do terreiro, também remeteria ao domínio terapêutico proporcionado pelo plantão.

Obviamente que essa compreensão etnopsicológica foi possibilitada não no exato momento do encontro no plantão psicológico, sendo importante, durante a escuta, atentar para o contexto de referência e para a cultura da qual a pessoa faz parte. A aproximação do terapeuta com esse universo possibilitou que o relato de Cristal fosse acolhido tendo como referência a umbanda, o terreiro, os costumes e as tradições ali veiculadas e corporificadas, o que foi fundamental para aceitá-la tal como se apresentava.

Nota-se que a comunidade se armou diante da presença de Cristal, que passou a ser considerada incômoda, talvez por disparar em cada um o próprio despreparo para acolher uma pessoa nessa situação de sofrimento mental ou com a "cabeça virada". "Barrá-la" no terreiro era uma reação ao seu sintoma ou aos desdobramentos do seu caso na comunidade, em um discurso que beira ao "não temos condições de ficar com você, sua mãe é quem deve cuidar de você". Esse posicionamento, obviamente, contrastava com o apoio espiritual oferecido no terreiro, onde toda e qualquer demanda era acolhida e encaminhada - casos de amores não resolvidos, problemas financeiros, pessoas em sofrimento emocional, apenas para citar alguns exemplos. Excluí-la seria, portanto, contrário à ideologia presente na comunidade: acolher dentro da caridade (Macedo, 2014). O pai-de-santo, atento a esse movimento, continuava a ouvir Cristal e suas dores fora dos atendimentos mediúnicos. Mesmo não concordando com o conteúdo do seu relato, entendia que se tratava de uma dificuldade "em sua cabeça" e que era necessário um tratamento ou mesmo uma escuta. No entanto, este tratamento não deveria excluir o terreiro, mas sim ser incorporado dentro das possibilidades de escuta ali existentes, tanto com os guias espirituais como com os profissionais de Psicologia. Ao não desistir do seu caso, mostrava a sua consideração positiva incondicional e a confiança em sua potencialidade para crescer, o que trazia Cristal novamente para aquele espaço de acolhimento e de compreensão. O fato dessa 
comunidade interpretar o caso de Cristal como um "problema de cabeça", o que possuía um lugar dentro do panteão umbandista e, portanto, na compreensão etnopsicológica, oferecia uma explicação religiosa (e cultural) para a sua dor, mas que necessitava de um apoio para além daquele ofertado nas consultas espirituais: era, pois, caso de Psiquiatria, de internação, de atendimento psicológico, de fontes de ajuda que ultrapassavam os limites do terreiro. No plantão psicológico, portanto, buscava-se escutar essa "cabeça" ainda não firme de Cristal, ajudando-a a ser organizar, a rever explicações, posicionamentos e compreensões acerca de si mesma, em uma linguagem acessível e que recuperasse elementos daquele contexto no qual estava imersa. Os elementos multiculturais e etnopsicológicos, portanto, estavam presentes no modo de ouvir as queixas, assimilá-las e reapresentá-las à Cristal em forma de uma compreensão genuína acerca do seu relato. A imersão do profissional na comunidade e sua atenção aos elementos etnopsicológicos foram importantes não apenas para a escuta naquele momento, mas também para a reflexão acerca do caso e das possíveis necessidades e ajustes para os próximos atendimentos ali desenvolvidos.

O terapeuta deve manter sua presença genuína, o que parece ser fundamental no contexto da atenção em saúde mental. Ser autêntico, respeitar as próprias crenças, ter consciência de suas limitações e de suas potencialidades é um passo importante que deve ser fomentado constantemente pelos terapeutas que se dedicam à abordagem centrada na pessoa (Amatuzzi, 2008; Justo, 2002). Nas palavras de Rosenberg acerca do pensamento de Rogers, "Eu só posso permitir o ser do outro até onde posso permitir-me ser. Para facilitar aos outros o alcançar de sua existência plena, eu preciso ser tudo que posso ser, a cada instante" (1977b, p.17). É preciso, com destaque para a interlocução entre as atitudes de autenticidade e de empatia, acreditar que o cliente pode se desenvolver, pode construir uma descrição mais positiva acerca de si, pode cuidar de sua saúde mental a partir da potencialização dos próprios recursos.

No caso de Cristal, as potencialidades podem ser compreendidas como a disponibilidade para estar com o outro e o interesse no espaço do atendimento psicológico como possibilidade de mudança de atitudes e comportamentos. Ela compreende a necessidade de ser ouvida, tanto que, ao final do atendimento, destaca que quer continuar com a "terapia" para que possa falar de suas questões, desabafar, colocar para fora o que sente. Acreditar no seu potencial para a autorrealização é fundamentalmente oferecer tempos e espaços para que esta cliente possa se perceber, vivenciar e compreender suas experiências de vida de modo mais integrado, por isso a importância do terapeuta.

$\mathrm{O}$ atendimento ocorreu em apenas um encontro, pois nem Cristal nem a mãe retornaram nas semanas seguintes. No entanto, o espaço 
do plantão foi reafirmado como possibilidade de acolhimento da urgência para toda a comunidade, devendo ser considerado como importante movimento no sentido de receber demandas que, de outra forma, poderiam ser escamoteadas ou resolvidas sem uma adequada reflexão. Os elementos etnopsicológicos e multiculturais atravessaram não apenas a intervenção, mas a compreensão do caso. O que era ter um "problema de cabeça" em uma comunidade na qual todos os médiuns haviam se desenvolvido também pelo fato de terem sido afetados em "suas cabeças"? O desenvolvimento mediúnico era apresentado como uma possibilidade de reorganizar "a cabeça", satisfazendo os guias espirituais e possibilitando que os mesmos continuassem a sua evolução espiritual por "trabalharem" na caridade. Para tanto, era preciso que o médium fosse um canal, um aparelho, um corporificador dessa experiência. Cristal, pelo modo como havia sido interpretada nas consultas espirituais, deveria desenvolver seu lado espiritual, cuidar "da sua cabeça", preparar-se para fazer a caridade.

No entanto, apesar da aceitação social e cultural desse percurso naquela comunidade, alguns elementos comportamentais de Cristal chamavam a atenção da comunidade, prescrevendo a ela um movimento de estigmatização e de exclusão, ainda que velado. Mas como era compreendida como alguém que precisava de ajuda, tinha um espaço na comunidade, nas giras e na própria atenção psicológica ali prestada e que se colocava em constante diálogo com a cultura e o contexto no qual se dava esse apoio. Conhecer essa cultura e seu modo de organização, bem como os rituais e as interpretações circulantes possibilitou que a equipe de psicólogos desenvolvesse uma escuta mais próxima da comunidade, incorporando esses aspectos como parte da compreensão acerca da pessoa em atendimento, o que torna a atenção psicológica em apreço um exemplo de incorporação dos pressupostos multiculturais e etnopsicológicos.

\section{Considerações finais}

No que se refere ao contexto da saúde mental, esta intervenção apresenta-se em consonância com os pressupostos do Sistema Único de Saúde e as novas políticas de saúde mental decorrentes da Reforma Psiquiátrica, que visam a compreender cada cidadão como um ser único que necessita de cuidados particulares, imerso em condições culturais, sociais e históricas que devem ser consideradas sempre. A despeito da prevalência de práticas em saúde mental que não compreendem o bem-estar integral da pessoa como um dos principais objetivos do tratamento, ou que possuem uma visão essencialmente focada na psicopatologia ou no diagnóstico como 
condição sine qua non para a atenção psicológica, a experiência de exercer uma Psicologia orientada positivamente e centralizada na pessoa é reveladora das potencialidades dos seres humanos, mesmo com certo grau de impedimento e comprometimento impostos pela psicopatologia, como afirmam Lemos e Cavalcante Junior (2009). Assim, a abordagem centrada na pessoa aplicada à saúde mental considera o indivíduo adoecido como uma pessoa com potencialidades e que deve ser reconhecido como tal pela sociedade, pelos profissionais de saúde e assistência social, pela sua própria família e pela comunidade, que recebe, interpreta, acolhe e questiona a pessoa em sofrimento, como no caso aqui ilustrado.

Não se trata, aqui, de destacar o terreiro de umbanda ou qualquer outro espaço religioso como um equipamento em saúde mental no bojo do movimento da Reforma Psiquiátrica. Pelo contrário, há que se destacar a importância do apoio profissional e especializado, atento às demandas e características das pessoas em sofrimento mental e articulado ao poder público. No entanto, o que apresentamos neste estudo de caso é uma leitura em saúde mental a partir de um serviço psicológico localizado em uma comunidade religiosa que congrega pessoas em busca de apoio, escuta e acolhimento de suas dúvidas e conflitos. Assim, esse acolhimento prestado alinha-se sim ao movimento que apregoa a necessidade de diversificar os espaços de atenção psicossocial e de oferta de cuidados em saúde mental. Ao caso em apreço, outras experiências poderiam aqui ser relatadas, mas priorizaram-se as características desse primeiro encontro entre terapeuta e cliente no contexto do plantão psicológico.

Por fim, há que se destacar que a complexidade da saúde mental deve ser beneficiada com o diálogo interdisciplinar e com a abertura para novas reflexões sobre uma escuta que se pretende ativa e propositiva de mudanças. A partir dos pressupostos da abordagem centrada na pessoa, da etnopsicologia e do aconselhamento multicultural, o acolhimento em saúde mental pressupõe a necessidade de que o terapeuta possa deixar o cliente à vontade para falar livremente, criando uma atmosfera de confiança e proximidade emocional que encoragem a pessoa a falar de seus conflitos, tendo como referência a comunidade, suas crenças e formas de organização. A possibilidade de encontro único, como relatado neste caso, destaca que a escuta deve ajustar-se a contextos e condições cada vez mais distantes dos ideais pressupostos de uma clínica hermética e que não dialoga com as mudanças sociais e culturais vigentes. Nesse sentido, o plantão adquire um status de intervenção potente em sua celeridade e profunda em sua capacidade de escuta. A consideração pelo contexto, pela umbanda e pelas características culturais da comunidade se respaldam em pressupostos do aconselhamento multicultural e do trabalho etnopsicológico. Abrirse ao diálogo com essas dimensões deve proporcionar, cada vez 
mais, a possibilidade de que a saúde mental realmente extrapole os equipamentos de saúde, estando a serviço de todos e sendo responsabilidade de cada um. O espaço do terreiro de umbanda mostrou-se acolhedor e também deflagrou a necessidade de que seus membros também possam ouvir frequentadores da comunidade, em uma postura de empatia e de consideração positiva pelo crescimento do outro.

\section{Referências}

Abelha, L., Gonçalves, S., Legay, L., Lovisi, G. M., Pereira, B. B., \& Fonseca, D. L. (2014). Limitações no comportamento social. In M. Bandeira, L. A. Lima, \& S. M. Barroso (Orgs.), Avaliação de serviços de saúde mental: Princípios metodológicos, indicadores de qualidade e instrumentos de medida (pp. 143-158). Petrópolis, RJ: Vozes.

Alves, M. C., \& Seminotti, N. (2009). Atenção à saúde em uma comunidade tradicional de terreiro. Revista de Saúde Pública, 43(supl. 1), 85-91.

Amatuzzi, M. M. (2008). Por uma psicologia humana ( $2^{\mathrm{a}}$ ed.). Campinas, SP: Alínea.

Barroso, S. M., \& Silva, M. A. (2011). Reforma Psiquiátrica Brasileira: O caminho da desinstitucionalização pelo olhar da historiografia. Revista da SPAGESP, 12(1), 66-78.

Bezerra, E. N. (2014). Plantão psicológico como modalidade de atendimento em Psicologia Escolar: Limites e possibilidades. Estudos e Pesquisas em Psicologia, 14(1), 129-143.

Bommert, H. (1987). Grundlagen der Gesprächspsychotherapie. Berlin: Kolhsmmer.

Cardoso, C. S. (2014). Qualidade de vida na esquizofrenia: Atualidades e perspectivas para o Brasil. In M. Bandeira, L. A. Lima, \& S. M. Barroso (Orgs.), Avaliação de serviços de saúde mental: Princípios metodológicos, indicadores de qualidade e instrumentos de medida (pp. 159-186). Petrópolis, RJ: Vozes.

Concone, M. H. V. B. (1987). Umbanda, uma religião brasileira. São Paulo: CER/EDUSP.

Csordas, T. (2008). Corpo/significado/cura. Porto Alegre: Editora UFRGS.

Gomes, F. M. D. (2008). Plantão psicológico: Novas possibilidades em saúde mental. Revista da SPAGESP, 9(1), 39-44.

Jorge, E. F. C. (2013). É no corpo que o santo baixa! Considerações sobre 0 corpo nos transes religiosos afro-brasileiros. Identidade!, São Leopoldo, 18(1), 122-132.

Justo, H. (2002). Abordagem centrada na pessoa: Consensos e dissensos. São Paulo: Vetor. 
Leal-de-Barros, M. (2013). "Os deuses não ficarão escandalizados": Ascendências e reminiscências de femininos subversivos no sagrado. Revista Estudos Feministas, 21(2), 509-534.

Leal-de-Barros, M., \& Bairrão, J. F. M. H. (2010). Etnopsicanálise: Embasamento crítico sobre teoria e prática terapêutica. Revista da SPAGESP, 11(1), 45-54.

Lee, D. L., Rosen, A. D., \& Burns, V. (2013). Over a half-century encapsulated: A multicultural content analysis of the Journal of Counseling Psychology, 1954-2009. Journal of Counseling Psychology, 60(1), 154-161.

Lei n. 10.216, de 06 de abril de 2001. Dispõe sobre a proteção e os direitos das pessoas portadoras de transtornos mentais e redireciona o modelo de assistência em saúde mental. Diário Oficial da União.

Lemos, P. M., \& Cavalcante Junior, F. S. (2009). Psicologia de orientação positiva: Uma proposta de intervenção no trabalho com grupos em saúde mental. Ciência \& Saúde Coletiva, 14(1), 233-242.

Macedo, A. C. (2014). Encruzilhada da interpretação: Cuidado e significação na umbanda. Pró-forma da Tese de Doutorado, Universidade de São Paulo, Ribeirão Preto, SP, Brasil.

Macedo, A. C., \& Bairrão, J. F. M. H. (2011). Estrela que vem do Norte: Os baianos na umbanda de São Paulo. Paidéia (Ribeirão Preto), 21(49), 207-216.

Macedo, A. C., Bairrão, J. F. M. H., Mestriner, S. F., \& Mestriner Junior, W. (2011). Ao encontro do Outro, a vertigem do eu: O etnopsicólogo em equipes de saúde indígena. Revista da SPAGESP, 12(2), 85-96.

Mahfoud, M. (2012). Plantão psicológico: Novos horizontes. São Paulo: Companhia Ilimitada.

Nascimento, G. C. M., Scorsolini-Comin, F., \& Peres, R. S. (2013). Mental health in the Unified Health System: Mapping the contributions from the Psychosocial Care Centers. SMAD Revista Eletrônica Saúde Mental Álcool e Drogas, 9 (2), 95-102.

Pagliuso, L., \& Bairrão, J. F. M. H. (2011). A etnopsicologia e o trabalho institucional em uma unidade de abrigo. Revista da SPAGESP, 12(1), 43-55.

Perches, T. H. P., \& Cury, V. E. (2013). Plantão psicológico em hospital e o processo de mudança psicológica. Psicologia: Teoria e Pesquisa, 29(3), 313-320.

Rogers, C. R. (1977). Em retrospecto: Quarenta e seis anos. In C. R. Rogers \& R. L. Rosenberg, A pessoa como centro (pp. 29-45). São Paulo: EPU.

Rogers, C. R. (2001). Tornar-se pessoa. São Paulo: Martins Fontes.

Rosenberg, R. L. (1977a). Introdução. In C. R. Rogers \& R. L. Rosenberg, A pessoa como centro (pp. 1-26). São Paulo: EPU. 
Rosenberg, R. L. (1977b). Terapia para agora. In C. R. Rogers \& R. L. Rosenberg, A pessoa como centro (pp. 49-68). São Paulo: EPU.

Scorsolini-Comin, F. (2015). Plantão psicológico centrado na pessoa: Intervenção etnopsicológica em terreiro de umbanda. Temas em Psicologia. (no prelo).

Scorsolini-Comin, F. (2014). Aconselhamento psicológico e psicoterapia: Aproximações e distanciamentos. Contextos Clínicos, 7(1), 2-14.

Scorsolini-Comin, F., \& Santos, M. A. (2013). Counseling Psychology: View of the scientific production in the Brazilian postgraduation. Journal of Human Growth and Development, 23(3), 338-345.

Sehgal, R., Saules, K. Young, A., Grey, M. J., Gillem, A. R., \& Nabors, N. A. (2011). Practicing what we know: Multicultural counseling competence among clinical Psychology trainees and experienced multicultural psychologists. Cultural Diversity and Ethnic Minority Psychology, 17(1), 1-10.

Stake, R. E. (2000). Case studies. In N. K. Denzin, Lincoln, Yvonna S. (Ed.), Handbook of Qualitative Research (2 ${ }^{\text {nd }}$ ed., pp. 134-164). Thousand Oaks, CA: Sage Publications, Inc.

Tassinari, M. A., Cordeiro, A. P. S., \& Durange, W. T. (2013). Revisitando o plantão psicológico centrado na pessoa. Curitiba: CRV.

Telles, T. C. B., \& Moreira, V. (2014). A lente da fenomenologia de Merleau-Ponty para a psicopatologia cultural. Psicologia: Teoria e Pesquisa, 30(2), 205-212.

Vidal, C. E. L., Bandeira, M., \& Gontijo, E. D. (2008). Reforma psiquiátrica e serviços residenciais terapêuticos. Jornal Brasileiro de Psiquiatria, 57(1), 70-79.

\section{Endereço para correspondência \\ Fabio Scorsolini-Comin}

Universidade Federal do Triângulo Mineiro

Departamento de Psicologia

Avenida Getúlio Guaritá, 159, Abadia, CEP 38025-440, Uberaba - MG, Brasil

Endereço eletrônico: fabioscorsolini@gmail.com

Recebido em: 30/06/2014

Reformulado em: 08/10/2014

Aceito para publicação: $15 / 10 / 2014$

\section{Notas}

* Psicólogo, mestre e doutor em Psicologia pela Universidade de São Paulo. Professor adjunto do Departamento de Psicologia da Universidade Federal do Triângulo Mineiro. 